\title{
Body index measurements in 1996-7 compared with 1980
}

\author{
A M Fredriks, S van Buuren, J M Wit, S P Verloove-Vanhorick
}

\begin{abstract}
Objectives-To compare the distribution of body mass index (BMI) in a national representative study in The Netherlands in 1996-7 with that from a study in 1980 . Methods-Cross sectional data on height, weight, and demographics of 14500 boys and girls of Dutch origin, aged 0-21 years, were collected from 1996 to 1997. BMI references were derived using the LMS method. The 90th, 50th, and 10th BMI centiles of the 1980 study were used as baseline. Association of demographic variables with BMI-SDS was assessed by ANOVA.

Results-BMI age reference charts were constructed. From 3 years of age onwards $14-22 \%$ of the children exceeded the 90th centile of $1980,52-60 \%$ the 50 th centile, and $92-95 \%$ the 10 th centile. BMI was related to region, educational level of parents (negatively) and family size (negatively). The $-0.9,+1.1$, and $+2.3 \mathrm{SD}$ lines in 1996-7 corresponded to the adult cut off points of 20,25 , and $30 \mathrm{~kg} / \mathrm{m}^{2}$ recommended by the World Health Organisation/ European childhood obesity group.

Conclusion-BMI age references have increased in the past 17 years. Therefore, strategies to prevent obesity in childhood should be a priority in child public health. (Arch Dis Child 2000;82:107-112)
\end{abstract}

Keywords: body mass index; reference values; Netherlands; obesity

Body mass index (BMI; weight/height ${ }^{2}$ ) as a measure for underweight and overweight is widely accepted. For adults, a pragmatic classification system exists, based on associations between body mass index and all cause mortality. ${ }^{1}$ Recently, BMI cut off values for adults were redefined and divided into six classes: < $18.5 \mathrm{~kg} / \mathrm{m}^{2}$, underweight; $18.5-$ $24.9 \mathrm{~kg} / \mathrm{m}^{2}$, ideal weight; $25.0-29.9 \mathrm{~kg} / \mathrm{m}^{2}$, preobese; $30.0-34.9 \mathrm{~kg} / \mathrm{m}^{2}$, obese class I; 35.0 $39.9 \mathrm{~kg} / \mathrm{m}^{2}$, obese class II; and $\geqslant 40 \mathrm{~kg} / \mathrm{m}^{2}$, obese class III. ${ }^{23}$

Compared with two other weight for stature indices $\left(\mathrm{kg} / \mathrm{m}\right.$ and $\left.\mathrm{kg} / \mathrm{m}^{3}\right)$ BMI better fits the conditions of low correlation with height and high correlation with weight and skinfold thickness. ${ }^{4}$

In children, BMI has been recommended as a measure for overweight, ${ }^{5}$ and child BMI age reference charts have been published in several countries. ${ }^{6-12}$ Because BMI is dependent on age and pubertal status, individual BMI values should be expressed as BMI standard deviation scores (SDS) for age. However, BMI-SDS can only be used as a parameter of overweight relative to the reference population and not in absolute terms, particularly if age references are regularly updated. Therefore, the international task force on obesity of the World Health Organisation (ITFO) and the European childhood obesity group (ECOG) ${ }^{5}$ suggested paediatric centiles identified by a BMI of 20, 25 , and $30 \mathrm{~kg} / \mathrm{m}^{2}$ in young adults as cut off values for the identification of underweight, overweight, and extreme overweight.

During the past two decades, a striking increase in the prevalence of obesity has occurred in Western countries, but also in fast industrialising countries and urbanised areas. In the USA, an alarming prevalence of obesity has been reported in children and adolescents ${ }^{13}$ since the early 1980s. In the UK, a striking increase in BMI, especially that of young women, was found over the years 1973 to $1988 .{ }^{14}$ In The Netherlands, weight for height values stabilised in the period 1965-80, and even slightly lower values at the level of the 90th, 50th, and 10th BMI centiles (P90, P50, and P10, respectively) were found from 3 months of age onwards. ${ }^{15} 16$

In our study, we present updated Dutch BMI reference charts, based on the fourth nationwide

Table 1 LMS values for body mass index $\left(\mathrm{kg} / \mathrm{m}^{2}\right)$ in Dutch 0-21 years olds in 1997, by age and sex

\begin{tabular}{|c|c|c|c|c|c|c|}
\hline \multirow[b]{2}{*}{ Age } & \multicolumn{3}{|c|}{ Boys $(n=7417)$} & \multicolumn{3}{|c|}{ Girls $(n=6960)$} \\
\hline & $L$ & $M$ & $S$ & $L$ & $M$ & $S$ \\
\hline \multicolumn{7}{|c|}{ Months } \\
\hline 1.0 & -0.62 & 14.42 & 0.086 & -0.09 & 14.01 & 0.087 \\
\hline 3.0 & -0.38 & 16.13 & 0.081 & -0.29 & 15.75 & 0.083 \\
\hline 6.0 & -0.22 & 17.15 & 0.078 & -0.35 & 16.70 & 0.082 \\
\hline 9.0 & -0.15 & 17.44 & 0.077 & -0.38 & 16.91 & 0.081 \\
\hline 12.0 & -0.12 & 17.35 & 0.076 & -0.43 & 16.82 & 0.080 \\
\hline 15.0 & -0.09 & 17.12 & 0.077 & -0.50 & 16.59 & 0.080 \\
\hline 18.0 & -0.06 & 16.87 & 0.077 & -0.60 & 16.37 & 0.079 \\
\hline \multirow{2}{*}{\multicolumn{7}{|c|}{ Years }} \\
\hline & & & & & & \\
\hline 2.0 & 0.01 & 16.42 & 0.079 & -0.82 & 16.07 & 0.078 \\
\hline 3.0 & -0.07 & 15.89 & 0.084 & -1.18 & 15.74 & 0.081 \\
\hline 4.0 & -0.38 & 15.61 & 0.088 & -1.42 & 15.51 & 0.087 \\
\hline 5.0 & -0.85 & 15.52 & 0.093 & -1.57 & 15.37 & 0.094 \\
\hline 6.0 & -1.32 & 15.52 & 0.097 & -1.66 & 15.47 & 0.102 \\
\hline 7.0 & -1.70 & 15.61 & 0.101 & -1.71 & 15.71 & 0.110 \\
\hline 8.0 & -1.95 & 15.82 & 0.104 & -1.73 & 16.00 & 0.117 \\
\hline 9.0 & -2.08 & 16.10 & 0.107 & -1.72 & 16.32 & 0.122 \\
\hline 10.0 & -2.13 & 16.43 & 0.110 & -1.69 & 16.72 & 0.126 \\
\hline 11.0 & -2.10 & 16.83 & 0.112 & -1.66 & 17.21 & 0.128 \\
\hline 12.0 & -2.02 & 17.32 & 0.113 & -1.63 & 17.82 & 0.128 \\
\hline 13.0 & -1.93 & 17.90 & 0.114 & -1.63 & 18.51 & 0.127 \\
\hline 14.0 & -1.82 & 18.54 & 0.115 & -1.64 & 19.19 & 0.126 \\
\hline 15.0 & -1.71 & 19.21 & 0.115 & -1.68 & 19.81 & 0.123 \\
\hline 16.0 & -1.59 & 19.85 & 0.115 & -1.73 & 20.34 & 0.121 \\
\hline 17.0 & -1.47 & 20.43 & 0.115 & -1.78 & 20.78 & 0.119 \\
\hline 18.0 & -1.33 & 20.94 & 0.115 & -1.83 & 21.16 & 0.117 \\
\hline 19.0 & -1.18 & 21.37 & 0.115 & -1.88 & 21.50 & 0.115 \\
\hline 20.0 & -1.04 & 21.75 & 0.115 & -1.93 & 21.80 & 0.113 \\
\hline 21.0 & -0.90 & 22.11 & 0.115 & -1.97 & 22.09 & 0.111 \\
\hline
\end{tabular}

$M$, median; S, coefficient of variation; $L$, the Box-Cox power transform required to remove the distribution's skewness. 

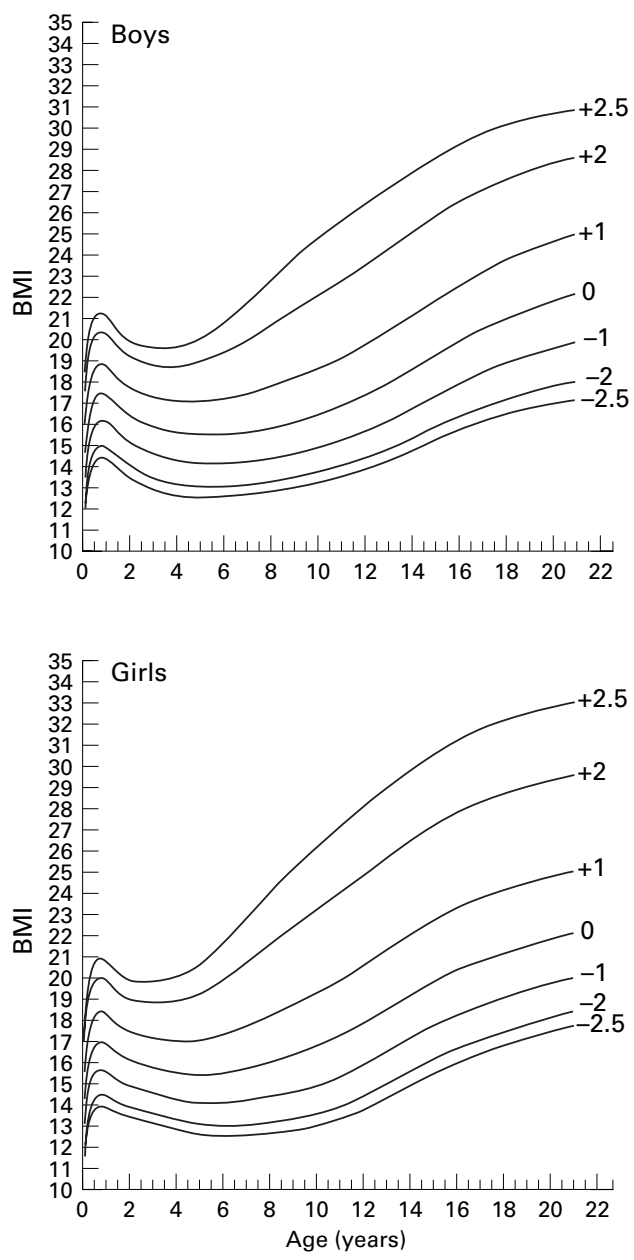

Figure 11997 body mass index (BMI) reference charts, for boys and girls 0-21 years, indicating -2.5 (0.6th), -2 (2nd), -1 (16th), 0 (50th), +1 (84th), +2 (98th), and +2.5 (99.4th) SD lines and their corresponding centile values.

growth study, performed in $1996-7 .{ }^{17}$ We evaluated the relations between BMI-SDS and geographical region, educational level, and family structures. We compared the distribution of BMI in the populations of 1997 and 1980, to assess whether the current epidemic of obesity has reached the Netherlands. In addition, the recommendations for identification of overweight children by the ITFO and ECOG were assessed using the 1997 and 1980 Dutch BMI data.

\section{Methods}

SUBJECTS

BMI reference charts were based on a cross sectional collection of growth data for 14500 children ( 7482 boys and 7018 girls) of Dutch origin, measured in 1996-7. The sample size was based on the aim of detecting a $1.8 \mathrm{~cm}$ height difference $(p=0.05)$ between the 1997 and 1980 growth studies (with a power of $99 \%) .{ }^{17}$ The sample was stratified by province, municipal size, sex, and age according to geographical distribution based on nationwide demographic data. ${ }^{17}$ The distribution of the total sample was found to be similar to national distributions, except for geographical region for girls aged $\geqslant 18$ years ( $\mathrm{S}$ van Buuren and
Table 2 Body mass index $\left(\mathrm{kg} / \mathrm{m}^{2}\right)$ values ( $-2 \mathrm{SD}, 0 \mathrm{SD}$, and +2 SD) in Dutch 0-21 year olds in 1997, for both sexes

\begin{tabular}{|c|c|c|c|c|c|c|}
\hline \multirow[b]{2}{*}{ Age } & \multicolumn{3}{|c|}{ Boys $(n=7417)$} & \multicolumn{3}{|c|}{ Girls $(n=6960)$} \\
\hline & $-2 S D$ & $O S D$ & $+2 S D$ & $-2 S D$ & $O S D$ & $+2 S D$ \\
\hline \multicolumn{7}{|c|}{ Months } \\
\hline 3.0 & 13.8 & 16.1 & 19.1 & 13.4 & 15.8 & 18.7 \\
\hline 6.0 & 14.7 & 17.2 & 20.1 & 14.2 & 16.7 & 19.8 \\
\hline 9.0 & 14.9 & 17.4 & 20.4 & 14.5 & 16.9 & 20.0 \\
\hline 12.0 & 14.9 & 17.4 & 20.3 & 14.4 & 16.8 & 19.9 \\
\hline 15.0 & 14.7 & 17.1 & 20.0 & 14.2 & 16.6 & 19.6 \\
\hline 18.0 & 14.5 & 16.9 & 19.7 & 14.1 & 16.4 & 19.3 \\
\hline 21.0 & 14.2 & 16.6 & 19.4 & 14.0 & 16.2 & 19.1 \\
\hline \multicolumn{7}{|l|}{ Years } \\
\hline 2.0 & 14.0 & 16.4 & 19.2 & 13.9 & 16.1 & 19.0 \\
\hline 3.0 & 13.5 & 15.9 & 18.8 & 13.6 & 15.7 & 18.8 \\
\hline 4.0 & 13.2 & 15.6 & 18.7 & 13.3 & 15.5 & 18.9 \\
\hline 5.0 & 13.1 & 15.5 & 19.0 & 13.0 & 15.4 & 19.2 \\
\hline 6.0 & 13.1 & 15.5 & 19.4 & 13.0 & 15.5 & 19.9 \\
\hline 7.0 & 13.1 & 15.6 & 20.0 & 13.0 & 15.7 & 20.7 \\
\hline 8.0 & 13.3 & 15.8 & 20.7 & 13.1 & 16.0 & 21.6 \\
\hline 9.0 & 13.5 & 16.1 & 21.4 & 13.3 & 16.3 & 22.4 \\
\hline 10.0 & 13.7 & 16.4 & 22.1 & 13.6 & 16.7 & 23.2 \\
\hline 11.0 & 14.0 & 16.8 & 22.8 & 13.9 & 17.2 & 24.0 \\
\hline 12.0 & 14.4 & 17.3 & 23.5 & 14.4 & 17.8 & 24.9 \\
\hline 13.0 & 14.8 & 17.0 & 24.2 & 15.0 & 18.5 & 25.7 \\
\hline 14.0 & 15.3 & 18.5 & 25.0 & 15.6 & 19.2 & 26.5 \\
\hline 15.0 & 15.8 & 19.2 & 25.7 & 16.1 & 19.8 & 27.2 \\
\hline 16.0 & 16.3 & 19.9 & 26.4 & 16.6 & 20.3 & 27.8 \\
\hline 17.0 & 16.8 & 20.4 & 27.1 & 17.0 & 20.8 & 28.3 \\
\hline 18.0 & 17.1 & 20.9 & 27.6 & 17.4 & 21.2 & 28.7 \\
\hline 19.0 & 17.4 & 21.4 & 28.0 & 17.8 & 21.5 & 29.0 \\
\hline 20.0 & 17.7 & 21.8 & 28.3 & 18.1 & 21.8 & 29.3 \\
\hline 21.0 & 17.9 & 22.1 & 28.6 & 18.4 & 22.1 & 29.6 \\
\hline
\end{tabular}

AM Fredriks, 1999, unpublished). Children with non-Dutch parents, children with diagnosed growth disorders, and those on medication known to interfere with growth were excluded. In contrast to previous Dutch growth studies, infants with a birth weight below $2500 \mathrm{~g}$ were included.

MEASUREMENTS

The measurements were standardised, and performed by trained health care professionals. Infants' length was measured to the nearest $0.1 \mathrm{~cm}$ in the supine position until 2 years of age. From 2 years of age, standing height was measured to the nearest $0.1 \mathrm{~cm}$. Infants up to 15 months of age were weighed naked, on calibrated baby scales. Older children were weighed, wearing underwear only, on calibrated mechanical or electronic step scales. Weight was recorded in log steps for infants, and rounded to the nearest $0.1 \mathrm{~kg}$ for older children. A questionnaire, filled in by a health care professional, was used to assess demographic variables. Provinces were clustered into four geographical regions. A fifth region was formed by four cities with more than 200000 inhabitants (Amsterdam, Rotterdam, Utrecht, and the Hague). Family size was defined by the number of children in a household $(1,2,3$, and $\geqslant 4$ ). The same categories were used for birth rank. The highest completed educational level of the parents was used as an indicator of socioeconomic status. The educational level of the child was determined at the time of measurement. If an adolescent of over 15 years of age had left the educational system, the highest completed education was recorded.

\section{STATISTICAL ANALYSIS}

The distribution of BMI in a population depends on age and tends to be positively skewed. The BMI reference centiles were 
Table 3 The mean (SD) age, BMI, and BMI-SDS for premenarcheal and postmenarcheal girls, in four age groups

\begin{tabular}{lrllrl}
\hline & $n$ & Age & BMI & BMI-SDS & $p$ Value \\
\hline $\begin{array}{l}11-12 \text { years } \\
\text { Premenarche }\end{array}$ & 293 & 11.5 & $17.6(2.8)$ & $-0.15(1.1)$ & $<0.001$ \\
$\begin{array}{l}\text { Postmenarche } \\
12-13 \text { years }\end{array}$ & 20 & 11.6 & $20.4(2.7)$ & $0.90(0.8)$ & \\
$\begin{array}{l}\text { Premenarche } \\
\text { Postmenarche }\end{array}$ & 218 & 12.5 & $18.0(2.8)$ & $-0.25(1.1)$ & $<0.001$ \\
$\begin{array}{l}\text { 13-14 years } \\
\text { Premenarche }\end{array}$ & 132 & 12.6 & $20.0(2.6)$ & $0.55(0.8)$ & \\
$\begin{array}{l}\text { Postmenarche } \\
\text { 14-15 years }\end{array}$ & 213 & 13.4 & $17.9(2.2)$ & $-0.55(1.0)$ & $<0.001$ \\
$\begin{array}{l}\text { Premenarche } \\
\text { Postmenarche }\end{array}$ & 50 & 14.4 & $20.0(2.6)$ & $0.29(0.9)$ & \\
\hline
\end{tabular}

derived using the LMS method. ${ }^{18}$ This method summarises the centiles by three smooth curves representing skewness ( $\mathrm{L}$ curve), the median (M curve), and coefficient of variation (S curve). The choice of the crucial smoothing parameters for the $\mathrm{L}, \mathrm{M}$, and $\mathrm{S}$ curves was made by creating local detrended QQ plots of the SDS of the reference sample across 16 age groups ( $\mathrm{S}$ van Buuren and AM Fredriks, 1999, unpublished). The curves were fitted as cubic splines. For boys, the effective degrees of freedom (edf) were equal to 13 (M curve), 5 (S curve), and 5 (L curve), and for girls, 11, 5, and 6 , respectively. The percentages of children in the 1997 growth study that exceeded the 10th,
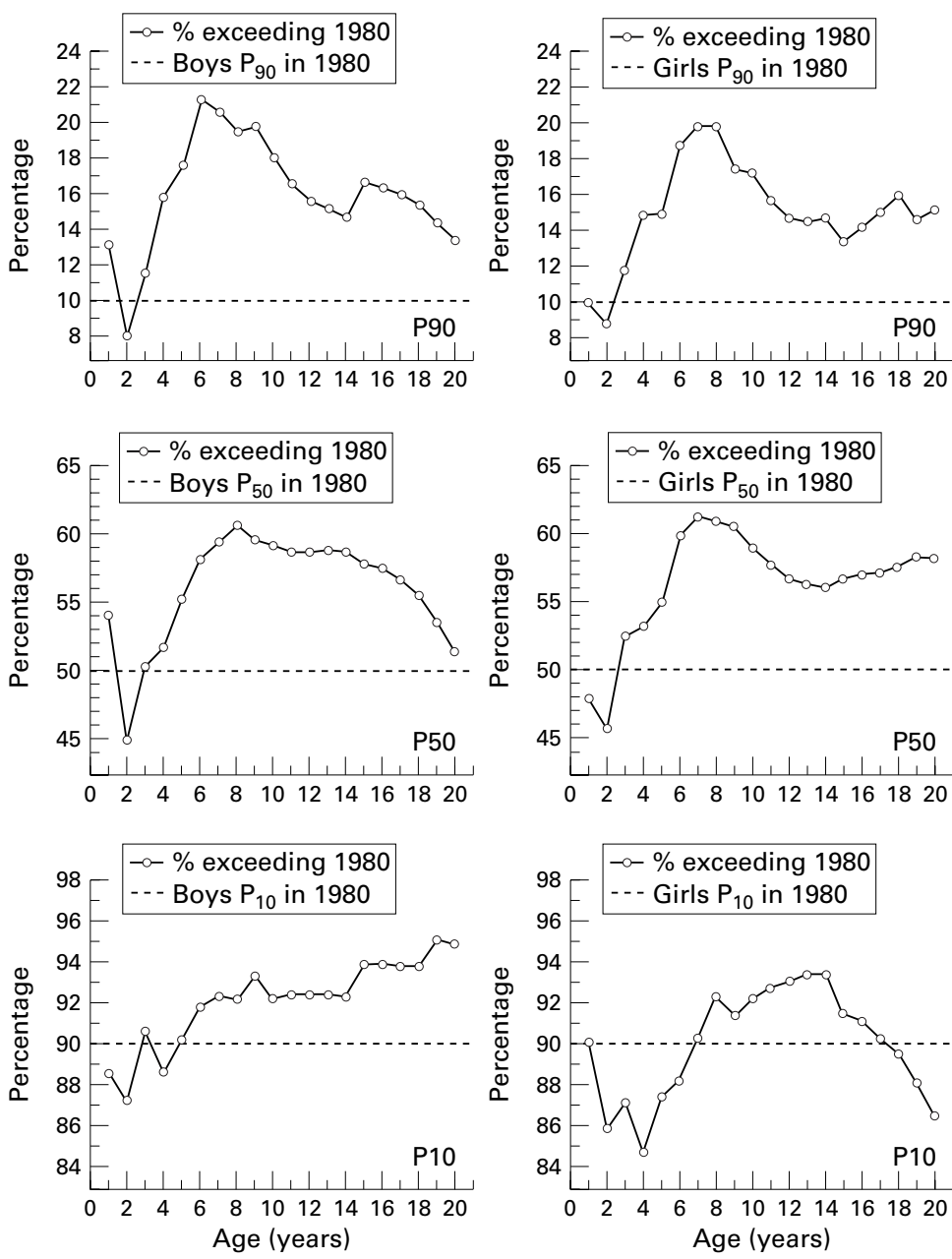

Figure 2 Percentages of boys and girls in 1997 that exceeded the P90, P50, and P10 of 1980 body mass index, 1-20 years of age. 50th, and 90th centiles for BMI in 1980 were calculated, ${ }^{11}{ }^{18}$ as were the percentages of 20 year old subjects who exceeded the cut off of 20,25 , and $30 \mathrm{~kg} / \mathrm{m}^{2}$ in both the 1997 and 1980 studies. The association of demographic variables (geographical region, family size, birth rank, and educational level (child and parents), and working outdoors (parents)) with $\mathrm{BMI}$ was assessed by univariate and multivariate analysis (ANOVA) of BMI-SDS. Mean BMI-SDS was calculated separately for premenarcheal and postmenarcheal girls and the difference was assessed by the Student's $t$ test.

\section{Results}

Table 1 summarises the fitted LMS curves for $\mathrm{BMI}$ by age and sex. L values of 1 indicate normality and smaller values represent progressively greater skewness. The $M$ curve is the 0 $\mathrm{SD}$ line or 50 th centile curve for BMI. The $\mathrm{S}$ curve defines the coefficient of variation, and multiplied by 100 it can be interpreted as a percentage. The coefficient of variation is about $8 \%$ in infancy, rising to $12-13 \%$ in adolescence.

Figure 1 shows the reference charts that correspond to the fitted LMS values, for both sexes, including the $0, \pm 1, \pm 2$, and $\pm 2.5 \mathrm{SD}$ lines, and provides the corresponding centile values. Table 2 gives the numerical values. The distribution is very skewed. The distance between the +2 and +2.5 SD lines is twice as wide as that between the -2.5 and -2 SD lines at all ages. In general, the median (0 SD) curves for boys and girls are very similar, although boys aged $0-1$ years have slightly higher BMI values. BMI increases steeply in early life, then it declines, and eventually flattens out at 5.5 years when BMI is approximately $15.5 \mathrm{~kg} / \mathrm{m}^{2}$. This dip in the BMI is called the "adiposity rebound". ${ }^{6} 19$ The age at adiposity rebound occurs earlier on the higher than the lower centiles, with a difference of up to 2 years. After the rebound, the BMI curves increase more rapidly in girls than in boys, until the age of 20 years. Table 3 illustrates that the mean BMI-SDS is significantly greater for postmenarcheal than premenarcheal girls in all age groups. Consequently, in clinical use, one should be aware of a difference of more than 0.8 BMI-SDS between premenarcheal and postmenarcheal girls. ${ }^{20}$

Figure 2 shows the difference in the BMI distribution between the 1997 and 1980 growth studies. From 3 years of age onwards, $14-22 \%$ exceeded the P90 of $1980,52-60 \%$ the P50, and 92-95\% the P10. Maximal differences were found at age 6 for both sexes: over $20 \%$ exceeded the 90th centile of 1980 and more than $60 \%$ the 50 th centile. The differences for the 10th centile were less obvious.

Figure 3 shows the effects of demographic variables on BMI-SDS. Univariately, mean BMI was significantly related to geographical region ( $p<0.0001)$, educational level of the parents $(p<0.0001)$, family size $(p=0.001)$, educational level of the child $(p=0.017)$, one or two parent families $(\mathrm{p}=0.001)$, and maternal employment $(p=0.05)$. Birth rank $(p=0.085)$ and working status of the father 

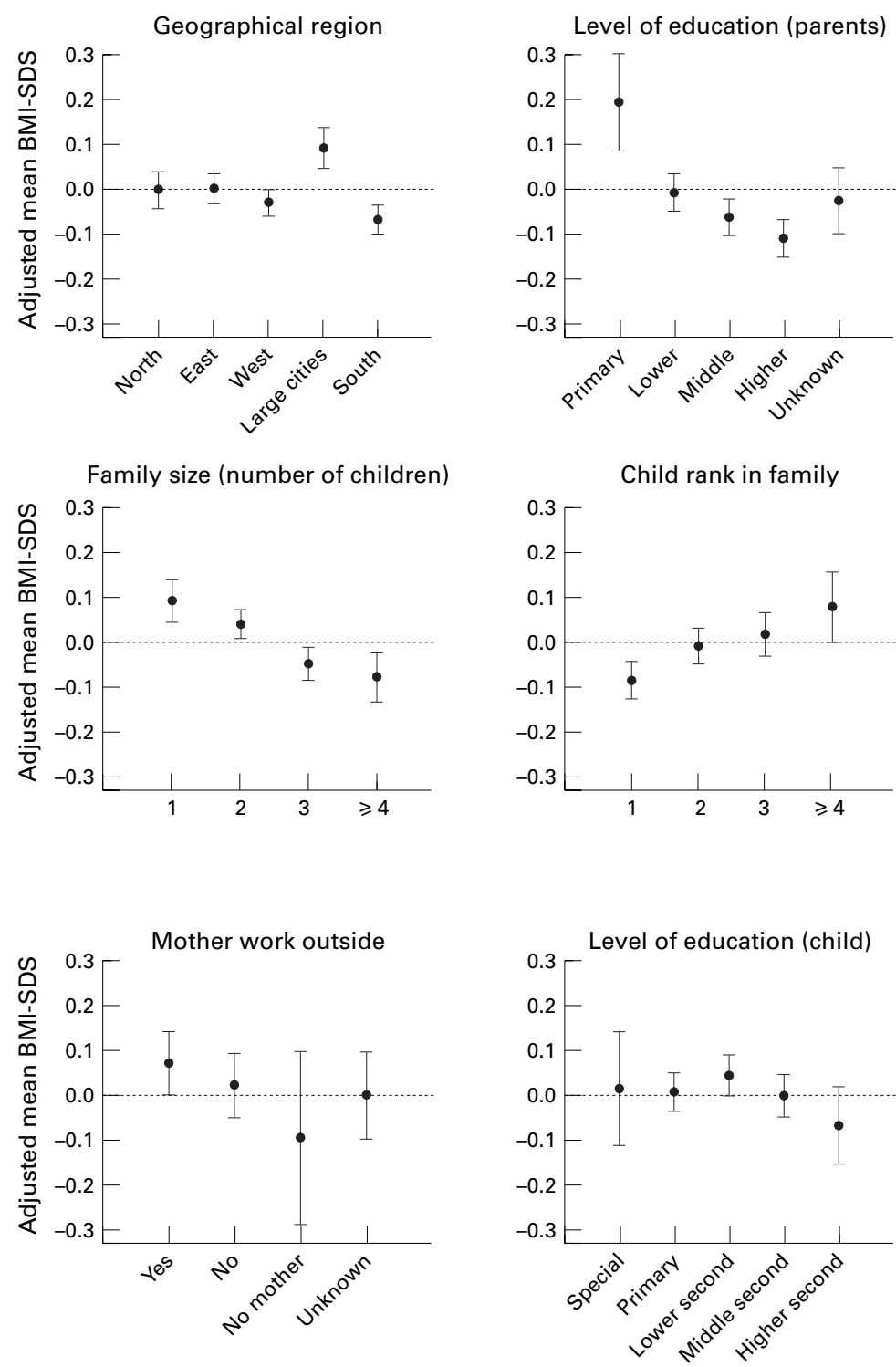

Figure 3 Mean body mass index standard deviation scores (BMI-SDS) (with their 95\% confidence intervals) for geographical region, level of parental and child education, family size, birth rank, and working status of the mother. Values are means adjusted for the effects of the other factors. For significance levels see text.

were not significantly related $(p=0.362)$. Multivariately, we found an association with BMI-SDS for geographical region $(\mathrm{p}<0.0001)$, educational level of the parents $(\mathrm{p}<0.0001)$, family size $(\mathrm{p}<0.0001)$, birth rank $(\mathrm{p}<0.0001)$, and the absence of the mother, illustrated by working outside the home $(p=0.019)$. The effect of the presence of the mother on the BMI-SDS, was supported by the positive correlation between the number of hours of outside employment and the BMISDS $(p=0.007)$. No significant association was found with the educational level of the child or one or two parent household. The effect of geographical region primarily related to large cities, which differs substantially from the rest. The relation between birth rank, family size, and BMI-SDS was complicated. Children with no siblings had a relatively higher mean BMI-SDS. However, within families, first born children tended to have a relatively lower mean BMI-SDS, and children showed increasing mean BMI-SDS values with higher rank of birth.

We compared the use of the cut off values of 20,25 , and $30 \mathrm{~kg} / \mathrm{m}^{2}$ in young adults in the 1997 BMI distribution with the 1980 distribution, because the latter has been suggested as an international standard. ${ }^{11}$ The percentages (1980 data in parenthesis) below the centile corresponding to adult BMI of $20 \mathrm{~kg} / \mathrm{m}^{2}$ in 1997 were $22.3 \%$ (19.8\%) for boys and $19.7 \%$ (27.5\%) for girls. Percentages exceeding $25 \mathrm{~kg} /$ $\mathrm{m}^{2}$ were $13 \%(9.9 \%)$ and $13.7 \%(8.8 \%)$, and above $30 \mathrm{~kg} / \mathrm{m}^{2}$ they were $0.9 \%(0.5 \%)$ and $1.5 \%(0.4 \%)$, for boys and girls, respectively. When we transformed these cut off values to SDs to identify the paediatric centiles (those for 1980 in parenthesis), we found that the $20 \mathrm{~kg} / \mathrm{m}^{2}$ cut off value corresponded to -0.8 SD $(-0.9)$ for men and $-0.9 \mathrm{SD}(-0.6)$ for women at 20 years of age. Similarly, a BMI of $25 \mathrm{~kg} / \mathrm{m}^{2}$ corresponded to $+1.1 \mathrm{SD}(+1.3)$ and $+1.1 \mathrm{SD}(+1.4)$ and a BMI of $30 \mathrm{~kg} / \mathrm{m}^{2}$ corresponded to +2.4 SD $(+2.6)$ and +2.2 SD $(+2.7)$, respectively. Thus, the $-0.9,+1.1$, and +2.3 SD lines in the 1997 BMI charts correspond approximately to the recommended limits for underweight, overweight, and extreme overweight, respectively.

\section{Discussion}

The current increase in the prevalence of youth obesity in Western countries has also occurred in the Netherlands, although during the period 1965-80 little difference had been found in weight for height. ${ }^{16}$ Therefore, it seems that the rise in obesity has taken place since 1980 . By 1997, the number of children exceeding the 1980 BMI 90th centile had almost doubled. The largest difference was seen at approximately 6 years of age, but overall the entire weight for height distribution has shifted upwards. This phenomenon corresponded to the reported positive secular change in height for age that has also occurred mainly in childhood. ${ }^{17}$ Overweight children tend to be taller, have advanced bone age, and mature earlier than non-overweight children, because height gain accelerates or follows shortly upon excessive weight gain. ${ }^{21}$

Age related BMI reference charts were constructed, based on data from the 1997 Dutch growth study. ${ }^{17}$ The BMI centiles rose steeply in infancy, fell during the preschool years, and rose again from 6 years onwards to $22.1 \mathrm{~kg} / \mathrm{m}^{2}$ for both sexes at 21 years of age. The age at which the adiposity rebound occurs is prognostic of overweight at adulthood. The age of rebound was 6 years in $1980^{11}$ and changed to 5.5 years in the 1997 growth study. The earlier the age of adiposity rebound, the greater the risk of adult obesity. ${ }^{19}{ }^{22}$ Although the current BMI centiles are based on a cross sectional study, it is striking that the lower centiles rebound later, by 3 years or more, than higher centiles. A similar phenomenon was found in the UK BMI reference charts. ${ }^{6} 7$

Weight is ultimately determined by the complex interaction of genetic ${ }^{2324}$ environmental, cultural, and psychosocial factors, acting through the physiological mediators of 
expenditure and energy intake. In general, it is assumed that the current rise in obesity is caused largely by environmental factors because genetic changes could not occur at this rate. ${ }^{25}$ Studies in the USA found no relation between the amount of physical activity and $\mathrm{BMI}$ in children, but higher BMI values were associated with watching more television, ${ }^{26}{ }^{27}$ although other studies found no (or weaker) correlations. ${ }^{28}{ }^{29}$ Furthermore, it is not clear if watching television is the cause or the consequence of being obese. ${ }^{28}$ A Dutch study found that $40 \%$ of children over 12 years of age spent more than two hours a day watching television. ${ }^{30}$ It may be that two mechanisms play a role-reduced energy expenditure as well as increased dietary intake during viewing or as a response to food advertising.

Contradictory results caused by methodological problems were also reported in studies that evaluate food consumption in obese and normal weight children. ${ }^{31}$ However, a consistent finding is that younger children with overweight parents consumed diets higher in fat than children with lean parents. A Dutch study reported that from 4 years of age onwards children's food patterns were similar to those of their parents. Comparisons among adolescents showed that the intake of fruit juices, soft drinks, and "invisible fats" has increased over the past decade. In addition, more snacks and sweets (candy) are eaten between regular meals, ${ }^{32}$ probably stimulated by the fact that increasing numbers of children and adolescents do not eat breakfast. This was observed more often in children of poorly educated fathers and children living in large cities. ${ }^{33}$

More overweight children were found in the four large cities studied. Therefore, we conclude that child public health care should concentrate particularly on preventing obesity in these urbanised areas in the Netherlands. In contrast to the impressive height differences between the northern and southern regions, ${ }^{17}$ no differences in BMI were observed between these regions. Raised BMI values were found in children with less well educated parents, the negative correlation with the educational level of the child disappearing in the multivariate analysis. Adult studies reported low educational level, low income, and urbanisation as risk factors for raised BMI. ${ }^{34}{ }^{35}$ Parental obesity strongly increases the risk of obesity, both in childhood and in adulthood. ${ }^{19} 3637$

The recommendation of the IOTF/ECOG to extrapolate the adult cut off values back to childhood would result in using the $-0.9,+1.1$, and +2.3 SD lines as cut off limits for underweight, overweight, and extreme overweight, respectively. Compared with the 1980 study, ${ }^{16}$ higher percentages of children were (extremely) overweight according to the proposed IOTF/ECOG classifications. The BMI value of $20 \mathrm{~kg} / \mathrm{m}^{2}$ for identification of underweight might be appropriate for a country such as the USA, but in the Netherlands this cut off would result in categorising more than $20 \%$ of children as underweight. The adult BMI cut off value of $18.5 \mathrm{~kg} / \mathrm{m}^{2}$ might be more useful; this would correspond to the paediatric $-1.8 \mathrm{SD}$ line, and consequently $4 \%$ of children would be categorised as underweight.

Weight for height ${ }^{\mathrm{n}}$ indices are cheap and easy to perform and calculate, and BMI (weight/ height ${ }^{2}$ ) is particularly useful in diagnosing overweight. Other advantages of the use of BMI in childhood are that it is widely accepted in adulthood, and that BMI charts are less affected by differences in timing of puberty than weight for height charts. However, SDS values must be used to allow for a more unbiased comparison between sexes and ages. ${ }^{38}$ In addition, it should be realised that BMI is dependent on stature (especially at younger ages) and sitting height, even though the denominator height ${ }^{2}$ was originally intended to correct for stature. Persons with short legs have relatively higher BMI values. ${ }^{39}$ Moreover, BMI and both fat mass and fat free mass in infancy correlate poorly. In children and adolescents the correlations range from 0.39 to 0.90 , depending on the method of body fat measurement and the age and sex of the subjects. ${ }^{40}$ In a minority of children heavy musculature can be confused with obesity.

Although obesity related morbidity is rare in childhood and adolescence, a few longitudinal studies have shown an association with increased adult morbidity and mortality (increased blood pressure, adverse lipoprotein profiles, non-insulin dependent diabetes mellitus, and atherosclerotic lesions). Depending on the applied definition of obesity, between $15 \%$ and $80 \%$ of obese children remain obese in adulthood because of tracking of their BMI. Because adverse health effects later in life might be consequent upon childhood obesity, ${ }^{41}$ we recommend that obesity prevention early in life should be a priority in child public health care.

In conclusion, we found an increase of BMI for age centiles in the Netherlands, especially in childhood and adolescence, compared with 1980. Taking a BMI of $25 \mathrm{~kg} / \mathrm{m}^{2}$ as the limit, $13.4 \%$ of young adults were overweight. This corresponded approximately to the paediatric +1.1 SD line in the 1997 reference charts. Children in large cities, with poorly educated parents showed relatively high mean BMI-SDS values. The observed rise in childhood obesity will probably result in increased adult obesity in the near future.

This study was carried out in cooperation with the "well baby clinics" and Municipal Health Services and was supported financially by The Ministry of Health, Welfare and Sports, Health Research and Development Counsel and Prevention, Nutricia, and Pharmacia and Upjohn. We thank Professor TJ Cole and Dr MJ Roede for providing the 1980 BMI data and also for their helpful suggestions.

1 Report of an Expert Committee. Physical status: the use and interpretation of anthropometry. Geneva: Word Health Organisation, 1995.

2 Prentice AM. Body mass index standards for children. BMF 1998;317:1401-2

3 International Obesity Task Force. Obesity: preventing and managing the global epidemic. Report of WHO consultation on obesity. Geneva: World Health Organisation, 1998.

4 Rolland-Cachera MF, Bellisle F, Sempé M. The prediction in boys and girls of the weight/height ${ }^{2}$ index and various skinfold measurements in adults: a two-decade follow-

5 Dietz WH, Robinson TN. Use of the body mass index (BMI) as a measure of overweight in children and adolescents. F Pediatr 1998;132:191-3. 
6 Cole TJ, Freeman JV, Preece MA. Body mass index reference curves for the UK, 1990. Arch Dis Child 1995;73: reference.

7 Hammer LD, Kraemer HC, Wilson DM, et al. Standardized percentile curves of body mass index for children and adolescents. Am F Dis Child 1991;145:259-63.

8 Leung SSF, Cole TJ, Tse LY, et al. Body mass index reference curves for Chinese children. Ann Hum Biol 1998; 25:169-74.

9 Lindgren G, Strandell A, Cole TJ, et al. Swedish population reference standards for height, weight and body mass index attained at 6 to 16 years (girls) or 19 years (boys). Acto Paediatr 1995;84:1019-28.

10 Rolland-Cachera MF, Cole TJ, Sempé M, et al. Body mass index variations: centiles from birth to 87 years. Eur $\mathcal{F}$ Clin Nutr 1991;45:13-21.

11 Cole TJ, Roede MJ. Centiles of body mass index for Dutch children aged $0-20$ years in 1980 - a baseline to assess children aged 0-20 years in 1980-a baseline to assess

12 White EM, Wilson AC, Greene SA, et al. Body mass index centile charts to assess fatness of British children. Arch Dis Child 1995;72:38-41.

13 Troiano RP, Flegal KM, Kuczmarski RJ, et al. Overweight prevalence and trends for children and adolescents. The National Health and Nutrition Examination Surveys, 1963 to 1991. Arch Pediatr Adolesc Med 1995;149:1085-91.

14 Gulliford MC, Rona RJ, Chinn S. Trend in body mass index in young adults in England and Scotland from 1973 to 1988. F Epidemiol Community Health 1998;46:187-90.

15 van Wieringen, JC, Wafelbakker F, Verbrugge HP, de Haas $\mathrm{JH}$. Growth diagrams 1965. Netherlands: Nederlands Instituut Praeventieve Geneeskunde, Leiden; WoltersNoordhoff, Groningen, 1971.

16 Roede MJ, van Wieringen JC. Growth diagrams 1980: Netherlands third nation-wide survey. Tijdschr Soc Gezondheidsz 1985;63(suppl):1-34.

17 Fredriks AM, van Buuren S, Burgmeijer RJF, et al. Continuing positive secular growth change in The Netherlands ing positive secular growth change

18 Cole TJ, Green PJ. Smoothing reference centile curves: the LMS method and penalized likelihood. Stat Med 1992;11: 1305-19.

19 Rolland-Cachera MF, Deheeger M, Bellisle F, et al. Adiposity rebound in children: a simple indicator for predicting obesity. Am f Clin Nutr 1984;39:129-35.

20 O'Dea J, Abraham S. Should body-mass index be used in young adolescents? Lancet 1995;345:657.

21 Dietz WH. Health consequences of obesity in youth: childhood predictors of adult disease. Pediatrics 1999; 101(suppl):518-25.

22 Rolland-Cachera MF, Deheeger M, Guilloud-Bataille M, et al. Tracking the development of adiposity from one month of age to adulthood. Ann Hum Biol 1987;14:219-29.

23 Bouchard C. The genetics of obesity: from genetic epidemiology to molecular markers. Mol Med Today 1995;1:45-50.

24 Ristow M, Muller-Wieland D, Pfeiffer A, et al. Obesity is associated with a mutation in a genetic regulator of
adipocyte differentiation. $N$ Engl f Med 1998;339:953-9.
25 Bray GA. Obesity: a time bomb to be defused. Lancet 1998; 352:160-1.

26 Gortmaker SL, Must A, Sobol AM, et al. Television viewing as a cause of increasing obesity among children in the United States, 1986-1990. Arch Pediatr Adolesc Med 1996; 150:356-62.

27 Andersen RE, Crespo CJ, Bartlett SJ, et al. Relationship of hysical activity and television watching with body weight and level of fatness among children. Results from the third national health and nutrition examination survey. $\mathscr{f} A M A$ $1998 ; 25: 938-42$.

28 Robinson TN. Does television cause childhood obesity? fAMA 1998;25:959-60.

29 DuRant RH, Baranowski T, Johnson $\mathrm{M}$, et al. The relationship among television watching, physical activity, and body composition of young children Pediatrics 1994:94:449-55.

30 Brugman E, Meulmeester JF, Spee-van der Wekke J, et al. Peilingen in de feugdgezondheidszorg, PGO-peiling 1993/1994. Peilingen in de feugdgezondheidszorg, PGO-peil.

31 Bosch JD, Legtenberg MGJ. Voedselconsumptie-onderzoek bij obese kinderen; evaluatie van methoden en resultaten.
(Food consumption studies in obese children: evaluation of (Food consumption studies in obese children: evaluation of research

32 Löwik MRH, Hulshof KFAM, van der Heijden LJM, et al. Changes in the diet in The Netherlands: 1987-88 to 1992. Int $\mathcal{F}$ Food Sci Nutr 1998;49:963-86.

33 Brugman E, Meulmeester J, Spee-van der Wekke J, et al. Breakfast-skipping in children and young adolescents in The Netherlands. European fournal of Public Health 1998;8: 325-8.

34 Mathus-Vliegen EMH. Overgewicht. II. Determinanten van overgewicht en strategieën voor preventie. (Overweight. II. Determinants of overweight and strategies for prevention.) Ned Tijdschr Geneeskd 1998;142:1989-95.

35 van de Mheen H, Stronks K, Looman CWN, et al. Does childhood socioeconomic status influence adult health through behavioural factors. Int $\mathcal{F}$ Epidemiol 1998;27:4317.

36 Whitaker RC, Wright JA, Pepe MS, et al. Predicting obesity in young adulthood from childhood and parental obesity. $N$ Engl f Med 1997;337:869-73.

37 Lake JK, Power C, Cole TJ. Child to adult body mass index in the 1958 British birth cohort: associations with parental obesity. Arch Dis Child 1997;77:376-81.

38 Van den Broeck J, Wit JM. Anthropometry and body composition in children. Horm Res 1997;48 (suppl):33-42.

39 Garn SM, Leonard WR, Hawthorne VM. Three limitations of the body mass index [editorial]. Am f Clin Nutr 1986;44: 996-7.

40 Barlow SE, Dietz WH. Obesity evaluation and treatment: expert committee recommendations. The Maternal and Child Health Bureau, Health Resources and Services Administration and the Department of Health and Human Services Pediatrics 1998;102:E29.

41 Pietrobelli A, Faith MS, Allison DB, et al. Body mass index as a measure of adiposity among children and adolescents: a validation study. F Pediatr 1998;132:204-10. 